Touching film:

the embodied practice and politics of film-viewing and film-making by

Anne Cranny-Francis

Department of Critical and Cultural Studies

Macquarie University 
This article addresses the corporeal or somatic experiences of film-viewing and film-making by focusing on the sense of touch. Touch is understood here as both a physical sensation and a cultural practice to which accrues particular meanings. Which is not at all to avoid the physicality of touch, but is to situate the physical as always already social, cultural and political. That is, as social beings we are always specifically located in terms of our corporeality, which already has meanings for us because of our (self-) perceived sex, gender, class, ethnicity, age, ability, race. In other words, embodiment is not an abstract or universal property of human (or other) being, but a specific, located and locatable, experience. And so the senses that constitute our embodiment - which include the sense of touch - are also specific, located and locatable. So, exploring the nature of touch at a particular time and place is not only a way of locating a particular experience of embodiment; it also tells us about the time and place in which that experience of touch happens.

By exploring the experience of touch in film, then, this essay achieves a number of aims. It reconceptualizes the experience of film-viewing as a form of somatechnics - a technology of embodiment, which associates particular sensations with particular meanings and, therefore, coerces the viewer to occupy a subject position associated with that complex of thought and feeling. This move acknowledges the role of all the senses, not only sight and hearing, in meaning making. In particular, the essay explores the power of the medium of film to manipulate or deploy the sense of touch, not conventionally associated with the viewing experience. This includes direct physical contact with the body of the viewer, as well as the sense of touching or being touched that may be generated through a synergistic meshing of different sensory stimuli. And the essay also interrogates the contemporary meaning of film as a medium, through an exploration of the different ways in which film touches and is touched. This includes not only the viewer's experience of being touched by the film, but also the film-maker's experience of touching the film. In particular, the essay explores the aims of the experimental film-maker whose transgressive touch challenges the transparency of the studio film, generating what one contemporary experimental film-maker describes as 'material affects' (Popescu 2006).

\section{Somatechnics: the embodied viewer}

In her essay, "What My Fingers Knew: The Cinesthetic Subject, or Vision in the Flesh" (2000) Vivian Sobchack writes about the way that film theory conventionally erases the embodied responses of the viewer from the process of analysis and meaning making. In so doing film theory reproduces the mind/body split that has characterised much western thinking (or, at least, much western thinking about thinking), relegating the somatic aspects of the viewing experience as the slightly embarrassing and debased side-effects of human embodiment. Sobchack notes that the sensuous is located, by this theory, either on screen, in the events of the narrative, or "off the screen in the spectator's fantasmatic psychic formations, cognitive processes, and basic sensory reflexes" (Sobchack 2000: 5). And the latter, she notes, are "'written 
off' as 'crude' phenomena that don't pose major questions of meaning" (Sobchack 2000: 5). In other words, this conventional film theory does not address the ways in which the sensory responses of viewers are a crucial part of the film's meaning-making practice. This omission leaves the sensory practice of film unchallenged; unlike the audio and visual components of film, its politics is not interrogated.

Yet, as Sobchack goes on to note, film viewing only makes sense (meaning) because it is "fleshed out": "the film experience is meaningful not to the side of my body, but because of my body." (Sobchack 2000: 5) Laura Marks addresses this experience through the concept of 'haptic visuality' (Marks 2000); her work is discussed later in this paper. In exploring how films touch us, and how we touch films, we are not just acknowledging an aspect of film viewing and meaning making that has conventionally been ignored, or actively suppressed (for example, as "crude"). We are also opening up the meaning potential of the film; that is, we are making available more of the meanings that film offers viewers, along with an understanding how those meanings are composed and deployed.

\section{Re-visiting the Feelies}

In his novel, Brave New World (1932) Aldous Huxley describes the movies, called 'The Feelies', that are part of the government's strategy of pacifying the public. In these movies viewers grasp the arms of their seats, which deliver sensations of touch and smell to enhance the sound and vision of the film. Huxley's description of the feelies is often read as a criticism of popular culture, conventionally associated with the 'baser' human senses such as touch and smell. When the 'Controller' of Huxley's novel describes the feelies as "nothing but pure sensation" (Huxley on-line), he locates them for Huxley's readers as degraded cultural forms, lacking the intellectual content of great art. Huxley's views were not uncommon; for many critics of the 1930s and beyond, the epithet, 'popular' was a marker of cheapness, of lack of value and of intellectual vacuity. It was also associated politically with the manipulation of working-class people, whose relationship with popular culture was assumed to be passive. Like Huxley's inhabitants of Brave New World they were described as ingesting popular culture as a kind of drug (called 'soma' in the book) that deadened them to the meaninglessness of their lives and the suppression of their innate abilities. The 'feelies' enhanced that dissociation from the world by transporting them to a realm of 'pure sensation', which was implicitly constructed as less significant than canonical western art. In this analysis the senses remain the degraded and degrading other of 'mind'; the physical perception that may even treacherously mislead the mind, as discussed in the writings of Plato (The Republic) and St Augustine (The Confessions) (Cranny-Francis, 1995: 3-4).

As Sobchack argues, this same perception informs much contemporary film theory and criticism, which thereby elides or suppresses much of the meaning-potential of the film. To remedy this omission I am going to explore how viewers are touched by film, with a focus on popular film - our contemporary feelies. I am not going to perform a sleight-of-mind and 
immediately metaphorise the object of inquiry; how do we feel - emotionally and how are we touched - emotionally - by the film? Instead I explore the embodied experience of being physically touched by film, which thereby creates the viewing subject - Sobchack's 'cinesthetic subject'; that is, the subject whose embodied being is (re)negotiated in the experience of film viewing.

\section{Sonic tactility}

In 2000 I took my five-year-old son to see the first of the 'new' Star Wars movies, Star Wars: The Phantom Menace (Lucas 2000). When the lights went down and the Dolby sound system kicked in with the famous John Williams theme, my son screamed and clamped his hands over his ears. Then he quickly picked up my hands and placed them over his hands over his ears - and that's how we watched the movie. The volume of the opening score, and the whole soundtrack, caused him physical pain; he was very literally 'touched' by the film.

In his book, The Soundscape (1994) Murray Schafer notes that people hear "from zero decibels to approximately 130 decibels (where sound sensation is converted to pain)." (Schafer 1994: 115) I'm sure that the score was not played at 130 decibels; however, my son was young, with unscarred eardrums, and for him the sound of the film was painful. And, in fact, most of the adults in the cinema gasped in both recognition and pain at the volume of the opening movement.

Schafer notes: "Hearing and touch meet where the lower frequencies of available sound pass over to tactile vibrations (at about 20 herz). Hearing is a way of touching at a distance ..." (Schafer, 1994: 11). Film has used this power of sound to touch the listener even before it became an audiovisual medium. Rick Altman records the many different sound accompaniments (voice, music, sound effects, and silence) used in conjunction with silent film, some of which parodied the film itself. As Altman notes, the relationship between the film soundtrack and visuals was determined consensually (between studios, filmmakers, and distributors) in the 1910s as one of enhancement or support, rather than of contrast and interrogation (Altman 2005). So, early in the twentieth-century, sound was deployed to support the project of the film-maker - essentially as a mode of suturing the viewer into the film narrative, not just conceptually, but through sensory engagement - as the body of the viewer vibrates to and with the sounds generated in the cinema.

Talking films introduced not only language but also sound effects and music to the film on screen, with a subsequent proliferation in the meaning potential of the film and its sensory appeal. Where the viewer of silent film once vibrated somatically to the piano or organ - and sometimes to a soundtrack created at a particular cinema - now she/he is pierced by the high pitched squeal of a locomotive; caressed by the warm tones of a honeyed contralto voice; shocked by the sharp discharge of a weapon; serenaded by a string quartet. More recent advances in film sound technology enable film-makers 
to separate and locate specific sound effects, which creates a sonic space occupied by the viewer. In this way the film engages two different touchrelated senses: the direct experience of touch, through the body's experience of sonic vibrations, and the proprioceptive sense. Proprioception is the body's sense of location in time and space, an internal positioning often associated with touch. By manipulating sound to create space, the film positions the body within the diegetic space of the narrative, not just the everyday space of the cinema. Maintaining this dual spatiality - the viewing subject simultaneously in the physical space of the cinema and the diegetic space of the narrative - requires a heightened sensitivity on the part of the viewer, a kind of self-touching that enables her/him to be simultaneously in both spaces, so that the diegetic world of the narrative can be experienced somatically - and its motivations and values explored in their own times. Simultaneously, the viewer can maintain her/his understanding that this is a mediated experience, so that the nature of the mediation can also be explored discursively.

\section{Sonic politics}

The sonic touch created by film is a distributed sense, a polymorphously perverse touch that affects the entire body of the viewer, most acutely, at high frequencies, through the eardrums, but at lower frequencies, vibrating the entire body. And when the proprioceptive sense is also engaged, then the filmic touch is more of a sensory mesh or net rather than a specific sensation such as a tap on the shoulder. Engaging the viewer corporeally in this way, then, resists the hierarchized logic of visual and verbal textuality, which position the viewer as rationalist subject, demanding the suppression of somatic responses in favour of conceptual argumentation.

Exploring the politics of this sonic tactility involves at least two different, but related, perspectives - the cinesthetic subject as consumer, and as viewer.

As noted above, one function of the sound is to suture the viewer into the narrative, so that the politics of the narrative have maximum impact on the viewing subject. That is, in negotiating the film, the viewer directly negotiates that politics, agreeing or disagreeing with its basic principles - so that the viewing experience is part of the formation of that subject. So when John Williams' martial music announces the beginning of the Star Wars saga, the viewer is drawn into a war of good versus evil, in the tradition of western mythology. The viewer is positioned to identify with the hero and against the villain - so that the politics of the hero, the beliefs, ideas and values that motivate his quest are given tacit approval by the viewing subject. And this is not simply an emotional or intellectual identification; through the sonic colonization of the viewing space by Lucas's soundtrack, the viewer is somatically implicated in the narrative.

Critical objections have been raised about George Lucas's use of sound in the Star Wars films, on the grounds that space is a vacuum and sound does not travel in a vacuum. Lucas's response is said to have been a rejection of any claim to verisimilitude in favour of the positive response of the audience to 
that rumble - which now has iconic sonic value. (By contrast consider the now, post-Lucas, disturbing silence of the spaceship in Tarkovsky's Solaris (1972); the difference became clear to me when an underground train rumbled through a tunnel below the cinema in which I was watching the film, transforming Tarkovsky's silent voyager momentarily into a Lucas starcruiser!). Another way to read Lucas's response is that the viewer's corporeal response to that rumble effectively sutures them into the diegetic world of his narrative; they literally 'feel' it, are touched by it.

Somatically a part of the narrative, viewers therefore find it very difficult to escape its cultural politics - even when that politics is hard to accept, as when the vision of an armed priest/Jedi/crusader seems to fulfil all the worst expectations of George W. Bush's imperial United States. And when the villains of the story speak a kind of Japlish; and the lovable buffoon character uncomfortably echoes the roles given to Black American performers in the 1930s and 1940s. Not that it is impossible to critique these characterisations, or challenge the narrative. However, if there is a tendency not to do so, even a resistance to such deconstructive practice, then the reason for the resistance may lie not with the audience's intellectual laziness or vacuity (as seems often to be implied or claimed), but with the powerful somatic effect, and affect, of the film - particularly its sonic power to touch the viewer.

As a consumer, however, the volume of the soundtrack has another (related) role. Murray Schafer writes that the freedom to subject people to loud sound is only available to those in a position of power in a society (Schafer 1994:

74). In medieval western society that power accrued to the Church, because of its power within the feudal state. So Church bells were among the loudest sounds to be heard in that high fidelity world, summoning the faithful to prayer. In the global capitalist world of the late twentieth- and early twentyfirst centuries, the power to subject citizens to loud sounds accrues to the state, state functionaries, and the successful capitalist entrepreneur, such as George Lucas. In the case of Star Wars the effect, and affect, of its opening sonic blast is to situate the viewer somatically not only within the diegetic world of the narrative, but also within the Lucas (consumer) empire. To label it a 'spectacle' is to conceal, visually, the role of sound - and so of touch (and therefore embodiment) - in the experience.

So the viewer is positioned by the viewing experience, which includes the touch of the film, not only as textual subject but also as consumer; to be part of the film's world by purchasing merchandise associated with it. This merchandise is used by the owner to reconstruct imaginatively the diegetic world of the text, and hence to continue, or maintain, the connection between viewer and text established in the viewing. And here it is interesting to note that touch has a more direct and conventional role, since the merchandise includes a range of objects that can be touched and manipulated by the viewer/purchaser. In other words, the viewer now re-creates the sensuous engagement with the story that has prompted the purchase.

Being touched by the sound of the film - sonically blasted by the opening movement of the score, vibrating with the low rumble of the spaceships 
through space - incorporates the viewer as cinesthetic subject into the diegetic world of the narrative, and into the consumerist world of late twentieth-century, and early twenty-first century, global capitalism. The politics of the viewing experience includes the politics of the narrative negotiated by the viewer, and the politics of the cinema experience - both of which are mediated by what Sobchack postulates as a chiasmatic third term, the carnal body of the viewer (Sobchack 2000). Exploring how the film touches the viewer somatically is one way into this analysis, and helps to explain the enormous success of texts that might otherwise be seen as quite limited, particularly in terms of dialogue and character development.

\section{Synergistic tactility}

Another means by which mainstream film touches the viewer is through the synergistic deployment of sonic, oral and visual stimuli; sound, words and images working together to touch the viewer. The synergistic touch I refer to here is what Laura Marks describes as 'haptic visuality' (Marks 2000: 162), though I want to put the focus on the sense of touch rather than sight. Synergistic tactility is a haptic complex of tactility (direct touch), proprioception (location in time and space) and kinesthesia (movement) and is best explained with an example.

In the recent Gothic horror film, Van Helsing (Sommers 2004), the character of Dracula is played with comic and/or erotic intensity by actor, Richard Roxburgh. The film itself revels in an almost scatalogical play with embodiment, with multiple scenes of bodily transformations, an extensive list of Gothic 'monsters' in the cast, and a specific focus on embodied difference through its central story-line, which concerns Dracula's attempts to vivify his born-dead offspring - the baby vampires in dripping liquid sacks of rotting amniotic fluid that are almost palpable (by touch and smell) to the viewer. In one scene the decadent aristocrat, Dracula dances with captured vampire hunter, Anna Valerious as he prepares to covert her into a 'bride' or 'undead' companion. The dance itself is a danse macabre, located in a baroque castle, filled with masked revellers and exotic entertainers (fire-eaters, stilt walkers), with a score that epitomizes aristocratic decadence - a Grand Guignol scene of excess - visually, sonically, even orally as the viewer enters the ballroom and a soprano begins a strange and beautiful song, a siren call.

Within this scene of sensory excess Dracula describes to Anna Valerious his desire that she become his 'bride', transformed into an undead or vampire like himself when he sucks the blood from her body. The oral eroticism of this scene is underscored by Dracula's voice and accent, as well as by his words. Dracula (Roxburgh) speaks with a version of the Romanian accent, familiar to viewers from over seventy years of Dracula movies (Bela Lugosi's version of the count in Dracula (Browning 1931) having iconic status). As Roxburgh reproduces the accent in this scene, it is breathy, soft, low, and spoken with the oral cavity relatively open (mouthy), generating a verbal erotics familiar to the role and echoed in his verbal exchange with Anna Valerious: for example, when she tells him, "You make my skin crawl", he responds, "That isn't all I 
could do with your skin" (where underlining marks the emphases in his speech).

Yet, Dracula's description of himself throughout this scene is of disembodiment; he laments to her his inability to feel - physically or emotionally. He demonstrates his lack of vitality, of embodied being, by clasping her hand over his heart so that she feels that his body is cold and without a heartbeat. And he dances with her before a large mirror in which only her body is visible, locked in an impossible embrace with an absent partner. Yet nowhere in the film is his body more obvious to the viewer, who is coerced into a haptic appreciation of his transgressive embodiment; we feel him, along with Anna Valerious.

That feeling - a sense of both touching and of being touched by him - is generated through the synergistic combination of stimuli in this scene: the baroque richness of the setting, the decadent and compelling music, rich and exotic costumes, the ritualistic movements of the dance sensuously echoed in the swirl of opulent fabrics, Roxburgh's erotic portrayal of Dracula (with its intertextual referencing of other, earlier versions of the character), his accent with its vocal mimicry of sexual arousal, and the fetishistic denial of his embodiment that only makes his body increasingly palpable. So when the viewer is presented with the mirror scene, Dracula's invisibility - his lack of embodiment - constitutes a visual analogue of desire, which the viewer hastens to fulfil, supplying the body (its feel, its deathly eroticism) that the image erases. The viewer does this through a simultaneous deployment of haptic senses (touch, self-location, movement) - generating a touch within the body of the viewer, constituted by a combination of proprioceptive and kinaesthetic processes (we squirm in our seats) - which is the erotics of this character and this situation.

\section{Political synergies}

I noted above, with reference to the politics of sound, that the touch generated by the soundtrack of a film works to interpellate the viewer into the narrative, positioning her/him within its political framework. The viewer (re)negotiates her/his subjectivity in response to that positioning, which is not only intellectual and emotional but also physical. Synergistic tactility operates in a similar way, though arguably the viewer works harder to create this synergy and accordingly may be more effectively positioned within and by the narrative.

Using the mechanism of synergistic tactility the viewer deploys the haptic senses in order to participate in the narrative, making this a heightened state of sensory involvement for the viewer. However the viewer engages voluntarily in this exercise as part of the viewing, so synergistic tactility is also open to denial by the viewer, who may refuse the offer made by the film to participate in this manner; a refusal that may be experienced as rejection, disgust, derision. For the engaged viewer, however, the politics of this situation is seductive; it may be very difficult for the viewer to refuse the political positioning offered by the narrative because she/he is physically, 
corporeally, engaged in creating that narrative and its politics. For example, it can be very difficult to disengage from the exhilarating battle scenes of Star Wars, with their multiple sensory stimuli, even if the politics they engage seem to be crude and to depend on offensive racial stereotypes - as with the 'Asianised' aliens, the Trade Ambassadors, at the very beginning of Star Wars: The Phantom Menace.

On the other hand, the fact that the viewer is heavily invested in this haptic construction of narrative (and meaning) may have another effect, which is that her/his own politics is incorporated (literally) into the narrative. This politics may reinforce that of the film narrative, but it may not; it may disrupt or contradict the narrative politics. Further, it makes it difficult to determine what the narrative politics is - that of the film-maker, or that of the viewer? This is not a new question for textual theory, ever since the emergence of 'reader response' criticism and studies of the phenomenology of reading and later of viewing; however, the question has conventionally been framed in conceptual/intellectual or political terms. That is, it has not taken account of this sensory engagement of the viewer, which reinforces the argument for viewer input into meaning-making. So the central issue raised in this reader response theory - is the film narrative constituted by the story and/or by the semiotics of the film or is it a relationship between the story, the semiotics of the film, and the embodied responses of the viewers? - can be reconsidered in terms of the sensory engagement of the viewer. And again, it seems valid to argue that the fact that viewers engage fully corporeally (not just conceptually) with film supports the claim that this corporeal engagement is an essential to the production of film narrative. Further, since embodiment is socially and culturally specific and located, film-makers rely on this shared being in order to tell stories and make meanings that are accessible to, and indeed partly generated by, their audiences.

So there are shared embodied responses to films that are deployed in the production of meaning, and they include the haptic (rather than primarily sonic) tactility of a film like Van Helsing. In this film the haptic tactility of a scene such as that described above, or of the scene in which the heroes encounter the baby vampires (which uses classic images of abjection to create an equal degree of palpability), is critical to the film's narrative of incommensurable difference and the moral dilemma it proposes.

\section{Touching film}

I want to conclude with a brief discussion of those film-makers whose work explicitly acknowledges the sensory engagement of the viewer with the film, experimental film-makers whose preoccupation is the meaning-making practice of the medium. I will refer specifically to an interview with experimental filmmaker, Stefan Popescu, winner of the 2006 Melbourne Underground Film Festival Award for Best Director. Popescu's work is heavily influenced by pioneers such as Stan Brackhage whose manipulation of film became increasingly 'hands on' as he scored, burned and painted the film stock. Popescu engages similarly with the materiality of the medium - and 
again my analysis concerns not only this embodied experience of touch (as film-maker), but also the meanings it creates in/as the film.

Popescu's aesthetic of 'Material Affects' - which I take to be the complex of meanings and feelings generated by the materiality of the medium - is a reaction against the efforts of mainstream filmmakers to maintain the transparency of their medium. Popescu notes that any scratch or marking of the film is for them a disaster, because it draws the viewer's attention to the medium and away from the overt 'subject' of the film - the film narrative. Yet this transparency elides the roles of both the filmmaker and the viewer in generating the narrative and its meanings: "what is concealed is the notion of the text as a site for the construction of meanings which should be considered and analysed in relation to the position, interests and intentions of their producers." (Masterman 1983: 5) For Popescu recognizing the materiality of the film is a crucial factor in the viewing experience, because it makes the viewer a part of the meaning making, part of the narrative. He foregrounds this materiality by touching the pristine film interface in a variety of ways - scratching, burning, using light exposures to create unusual optical effects that appeal directly, viscerally. In this way, Popescu's aesthetic is very similar to what Marks describes as 'haptic cinema': "Many prohaptic properties are common to video and film, such as changes in focus, graininess ... and effects of under- and overexposure. All of these discourage the viewer from distinguishing objects and encourage a relationship to the screen as a whole" (Marks 2000: 171-172). Popescu notes: "Firstly, with Material Affects, the material has a narrative responsibility; it's there to convey something more than itself, to signify something more than itself." He distinguishes his aesthetic from that of structuralist materialist film, which he describes as "foregrounding the actuality of film. ... It couldn't signify anything; it couldn't convey narrative." (Popescu 2006) For Popescu the embodied interaction of the viewer with his film generates the narrative. Like Ingmar Bergmann, whose work he admires, Popescu believes communication - and film as communication - is a fully embodied practice, neither simply verbal nor simply visual:

And that's what I'm trying to do with this idea of Material Affects that there are associations and metaphors and parallels through the material I wanted the film to carry through and if you can structure it right then it will carry through on a subconscious, or a physical, level. I don't want to say subconscious because that puts a hierarchy on the senses. (Popescu 2006)

Popescu's aesthetic focuses around the notion of identification: in his words, "I'm drawing a parallel between the cinematic body as a point of identification for the spectator's body so it's relating directly to their bodies." (Popescu 2006) So, for example, his film, "Terrorist TV" (2005), made just one week after the attack on the World Trade Centre, begins with the 5,4,3,2,1, countdown familiar from old film and television, and comprises a pastiche of images from popular television (including The Simpsons), various film genres including commercials 
and pornography, news broadcasts including images of George Bush and Osama Bin Laden, along with images of a plane hitting one of the towers of the World Trade Centre and others of the Towers burning, accompanied by a striking soundtrack that features some documentary and news voice-overs that are slowed down until the distortion makes them incomprehensible.

Popescu's film is constituted by, and constitutes, fragmentation, distortion, and decay: not directly in the images of the text (except for the images of the twin Towers), but in their juxtapositions, rapid editing, and burning out; and in the warping of the sound. This deformation of the body of the film is a point of identification for the body of the viewer (in Popescu's own terms), who may thereby experience the deformation and destruction that is the subject of the film - of those trapped in the Towers; of those in the countries opposed to the U.S.; of the U.S. media, dominated by government propaganda; of the U.S. government itself. For him, the Material Affects that are the result of his physical manipulation of the film - his touch as director - generate a corporeal, not simply intellectual, response in the viewer, because they demand such a complete sensory input from the viewer. That is, where mainstream 'clean' film presents its story as if through a plateglass window, Popescu substitutes an etched window, which draws the viewer's attention firstly to the window itself (so that she/he recognizes that this is a mediated experience) and secondly engages the viewer in predicting what the etching might conceal (or reveal), using her/his acculturated and embodied knowledge of both the medium and the events portrayed to create the narrative.

\section{Touching politics}

Like much non-realist art, experimental film such as that of Popescu engages the viewer directly in the process of meaning-making, because there is no simple, familiar realist positioning for the viewer to adopt. Instead the viewer has to work for the meaning - and for Popescu this work is a fully embodied practice, engaging the senses not in subjection to the intellect, but as a crucial part of the meaningmaking. Accordingly, a number of his films use physically shocking or confronting images in order to engage the viewer directly and to demonstrate that this engagement is not simply an intellectual game.

I shall not repeat here the earlier description of viewer engagement with film, though all of this applies to experimental film, but simply note that the touch of the filmmaker is an equally political exercise. The director's choice to mark the film-stock creates a very different relationship with the viewer, though Popescu notes that the filmmaker's role is equally directive: he describes film-makers like himself as deliberately creating what Virillio calls 'the accident' so that they can control its potential for meaning-making (Popesu 2006). So this is not a laissez-faire notion of semiosis, nor a version of 'art-for-art's-sake'; rather Popescu's intention is to give viewers access to the cultural 
meanings and embodied experiences that we all share, rather than leave them implicit and unexamined as in the realist text. His director's touch is intended to touch the viewer corporeally, by inviting her/him to view the film as an embodied experience to which she/he contributes located and somatic knowledge in order to generate a narrative.

\section{Concluding touch}

In film, touch is a critical feature of the viewing experience, which is used both to suture the viewer into the film narrative, and (sometimes) to interrogate that suturing process. Touch, as a located cultural practice, also provides the viewer with a way of resisting that same suturing, enabling her/him to interrogate the assumptions of the film and the film-maker. As well, touch is a means by which a filmmaker may disrupt the medium of film, inviting viewers to assess critically both the medium and its narratives. Most importantly, realizing the crucial role of touch in film viewing and (some) film making enables us to reincorporate the experience of film, acknowledging its engagement with and deployment of the senses, not only the intellect, in the generation of film narrative. Which simultaneously allows us to interrogate the way in which film itself operates as a form of somatechnics, a technology of the body that incorporates viewers into the politics of the film narrative and into the global enterprise that is contemporary film-making. 


\section{References}

Altman, Rick. (2005) Silent Film Sound. New York: Columbia University Press.

Cranny-Francis (1995) The Body in the Text. Melbourne: Melbourne University Press.

Huxley, Aldous. (1932) Brave New World, viewed on-line (24/8/2006) at http://www.huxley.net/bnw/sixteen.html

Marks, Laura U. (2000) The Skin of the Film: Intercultural Cinema, Embodiment, and the Senses. Durham and London: Duke University Press.

Masterman, Len. (1983) "Media Education: Theoretical Issues and Practical Possibilities." Metro, 60: 5-10.

Popescu, Stefan. (2006) "Interview." Unpublished.

Schafer, R. Murray. (1994) The Soundscape: Our Sonic Environment and the Tuning of the World. Destiny: Rochester, Vermont.

Sobchack, Vivian. (2000) "What My Fingers Knew: The Cinesthetic Subject, or Vision in the Flesh." Senses of Cinema: viewed online $(08 / 01 / 2006)$ at http://www.sensesofcinema.com/contents/00/5/fingers.html

\section{Filmography}

Browning, Tod, dir. (1931) Dracula. Universal.

Lucas, George, dir. (2000) Star Wars I: The Phantom Menace.

TCF/Lucasfilm.

Popescu, Stefan, dir. (2005) "Terrorist TV" in Repressions: Screenworks by Stefan Popescu. Sydney Film School.

Sommers, Stephen, dir. (2004) Van Helsing. Universal.

Tarkovsky, Andrei, dir. (1972) Solaris. Sovcolor/Scope Mosfilm 